\title{
A Audiência de Gestão Democrática na perspectiva da Concepção Jurídica Procedimentalista
}

\author{
The Democratic Management Hearing in the Perspective of the \\ Procedimentalist legal Concept
}

\author{
Tarcisio Vieira Gonçalves ${ }^{1}$ \\ Leandro Corrêa de Oliveira ${ }^{2}$
}

\begin{abstract}
RESUMO
O presente artigo analisa o modelo da audiência de gestão democrática do processo a partir de uma concepção procedimentalista do direito. A questão levantada é se, e como, essa metodologia pode contribuir para a implementação do processualismo constitucional democrático. Para tanto, vale-se dos métodos analítico e bibliográfico e dos aportes teóricos de Habermas e Nunes. Constata-se que a audiência, marcada pela oralidade, é um importante instrumento na busca pelo atingimento daqueles objetivos, tendo em vista consagrar as noções de comparticipação e policentrismo.
\end{abstract}

\section{PALAVRAS-CHAVE:}

Audiência, Gestão democrática, Procedimentalismo, Processualismo constitucional.

\begin{abstract}
This article analyzes the model of the hearing for democratic process management from a proceduralist conception of law. The question raised is whether, and how, this methodology can contribute to the implementation of the democratic constitutional processualism. Therefore, the analytical and bibliographic methods and the theoretical contributions of Habermas and Nunes are used. It is observed that the hearing, known by orality, is an important instrument in the search to reach those goals, in order to consecrate the notions of copartnership and polycentrism.
\end{abstract}

\section{KEYWORDS:}

Democratic management hearing, Proceduralism, Constitutional processualism.

\footnotetext{
${ }^{1}$ Mestrando em Direito na área de concentração Constitucionalismo e Democracia pela Faculdade de Direito do Sul de Minas (FDSM). Advogado.

${ }^{2}$ Doutor (Universidade Estácio de Sá, UNESA) e Mestre (Universidade Federal do Paraná, UFPR) em Direito do Estado. Professor dos cursos de graduação e mestrado da Faculdade de Direito do Sul de Minas (FDSM). Atualmente pesquisando a interação entre jurisdição e política. Advogado.
} 


\section{INTRODUÇÃO}

Convive-se no Brasil com o aparentemente insuperável entrave do Poder Judiciário, sempre alegadamente assoberbado de trabalho, desprovido de corpo técnico em quantidade e qualificação necessária, sem estrutura física e organizacional suficiente. Identifica-se um modelo neoliberal de processo $^{3}$, em que a meta é a redução do acervo de demandas no menor tempo possível, mas não a qualidade das decisões judiciais. Entretanto, essa dinâmica atualmente praticada urge ser revista. O modelo constitucional de processo não admite esse cenário. Por conseguinte, torna-se salutar a discussão teórica aqui eriçada, de uma proposta apta a contribuir na superação dessa dificuldade histórica.

Daí o tema do presente estudo: a audiência de gestão democrática, que é um modelo que vem sendo adotado em processos de recuperação judicial e de falência, revelando êxitos, sobretudo na oferta de soluções adequadas e em prazo razoável nessas demandas, além de outras tantas vantagens como a participação efetiva das partes na decisão, maior comprometimento dos atores processuais, colaboração e transparência ${ }^{4}$. O que se objetiva é analisar se essa metodologia pode ser aplicada em qualquer espécie de processo judicial ${ }^{5}$, se se insere no paradigma da concepção jurídica procedimentalista, bem como se contribui para a efetivação do processualismo constitucional democrático. Considera-se, em hipótese, que tal

\footnotetext{
3 "No Brasil, devido à ausência de formação, preparação dos profissionais, infra-estrutura e, mesmo, vontade política, foi sendo delineado um modelo neoliberal de processo.

Essa perspectiva, constituída, de modo sub-reptício, pelo discurso do Banco Mundial e pela política de mercado brasileira, vai intriduzindo no discurso processual a busca a qualquer preço da obtenção de procedimentos extremamente rápidos [...].

Cria-se mesmo em todos uma sensação de que o espaço-tempo processual é um mal que deve ser estirpado mediante a máxima produtividade, rapidez procedimental, sumarização cognitiva extrema e julgamento em massa de feitos, mediante técnicas que reduzem a cognição e o espaço público de problematização endoprocessual. O Direito, nessa perspectiva, não deve ser aplicado em cada caso concreto, mas, sim, em larga escala, mesmo em demandas singulares [...]", conforme NUNES, Dierle José Coelho. Processo Jurisdicional Democrático: Uma Análise Crítica das Reformas Processuais. 1. ed. 3. reimpr. Curitiba: Juruá, 2011, p. 254-255.

${ }^{4}$ COSTA, Daniel Carnio. Reflexões sobre processos de insolvência: divisão equilibrada de ônus, superação do dualismo pendular e gestão democrática de processos. Cadernos Jurídicos da Escola Paulista de Magistratura, São Paulo, ano 16, n. 39, p. 59-77, jan./mar. 2015, p. 75-76.

${ }^{5}$ Utiliza-se o termo "processo" na dicção fazzalariana, adotada por Nunes, de que o processo é um procedimento dinâmico e dialético em que se garante o direito de participar na formação do provimento a todos aqueles que puderem ter sua esfera jurídica afetada por esse provimento, ou seja, o processo afasta a centralidade protagonista do juiz mediante a participação em contraditório, visando conferir legitimidade à jurisdição (NUNES, Dierle José Coelho. Da Teoria Fazzalariana de Processo - O Processo como Espécie de Procedimento Realizado em Contraditório e a Difusão dos Módulos Processuais como Mecanismo de Controle da Função Estatal. Revista IOB Direito Civil e Processual Civil, São Paulo, ano VIII, n. 43, p. 212-215, set./out. 2006).
} 
modelo visa garantir aos atores do processo participação e influência de modo paritário, afastando a figura do juiz detentor da última palavra e única correta, mas colocando-o ao lado dos interessados na busca pela construção da melhor decisão.

O desenvolvimento desta pesquisa, guiado pelos métodos analítico e de pesquisa bibliográfica, vale-se das contribuições teóricas de Jünger Habermas, com sua concepção procedimentalista do direito, e de Dierle Nunes, com a proposta de comparticipação e policentrismo no âmbito de processo constitucional democrático.

\section{O PROCEDIMENTALISMO NA PERSPECTIVA DE JÜRGEN HABERMAS}

O direito é um medium linguístico de transposição de estruturas de interações simples e relações de solidariedade natural para o contexto de uma sociedade diferenciada funcionalmente ${ }^{6}$. Habermas fornece o mote do presente artigo, no qual se pretende analisar como, e por quais instrumentos, o direito pode ser exercício da democracia.

Se as sociedades atuais são complexas, o relacionamento dos homens que nela vivem também é e, igualmente assim, o modo de solucionar os problemas que os aflige. Daí o direito, destinado a ser o caminho por meio do qual se pode chegar às soluções. Isso porque "a linguagem do direito pode funcionar como um transformador na circulação da comunicação entre sistema e mundo da vida"7. Não basta, para Habermas, o agir estratégico - preocupado com o sucesso e não com a razão e a ética do discurso. Na sociedade complexa, é imprescindível a ação comunicativa para a produção de consensos, único modo de produção racional de escolhas democráticas.

No entanto, é preciso distinguir que no agir comunicativo há um comportamento um tanto ingênuo. Por sua vez, no discurso vence a força do melhor argumento, de tal modo que as

\footnotetext{
6 HABERMAS, Jünger. Direito e democracia: entre facticidade e validade. Tradução de Flávio Beno Siebeneichler. Rio de Janeiro: Tempo Brasileiro, 1997, v. II, p. 45.

${ }^{7}$ Id., Direito e democracia: entre facticidade e validade. 2 ed. Tradução de Flávio Beno Siebeneichler. Rio de Janeiro: Tempo Brasileiro, 1997. v. I, p. 112.
} 
pretensões de validade são analisadas à luz das razões e dos argumentos intersubjetivamente $\operatorname{expostos}^{8}$ :

O discurso, portanto, é uma ética comunicativa formal e procedimental, baseada em pressupostos pragmáticos universais de argumentação que garantem, contrafaticamente (normativamente), as condições ideais sob as quais os participantes de uma interação podem chegar a um consenso pelo melhor argumento, isto é, um consenso como resultado do assentimento do grupo a respeito das pretensões de validade levantadas na argumentação?.

Pela teoria do discurso, o direito, portanto, será considerado legítimo quando os destinatários de uma norma - simultaneamente sujeitos políticos, mas também singulares -, de maneira livre, não coativa, em um discurso racional - leia-se, organizado comunicativamente - consensualmente a estabelecerem e a reconhecerem como tal ${ }^{10}$. Significa dizer que o direito será legítimo quando os destinatários da norma forem também seus autores ${ }^{11}$.

Daí "o processo democrático condiciona a criação do direito legítimo a um tratamento presuntivamente racional de problemas" ${ }^{12}$. É o processo democrático que legitima o processo de criação do direito, em superação ao republicanismo e ao liberalismo ${ }^{13}$. Habermas considera, pois, comprometidos tanto o paradigma jurídico liberal, fundado na ideia de liberdades e propriedade, quanto o do Estado social, centrado na busca pela igualdade de chances ${ }^{14}$, e propõe o câmbio para um novo paradigma do direito: "surge agora uma concepção jurídica procedimentalista"15.

Habermas é um pós-positivista daquilo que se convencionou designar de procedimentalismo. Essa ideia da forma, do procedimento, das etapas e condições é central no

\footnotetext{
8 HABERMAS, Jünger. Entre naturalismo e religião: estudos filosóficos. Tradução de Flávio Beno Siebeneichler. Rio de Janeiro: Tempo Brasileiro, 2007, p. 23.

9 SIMIONI, Rafael Lazzarotto. Direito e Racionalidade Comunicativa. A Teoria discursiva do direito no pensamento de Jurgen Habermas. Curitiba: Juruá, 2007, p. 87.

${ }^{10}$ HABERMAS, Jünger. Sobre a Coesão Interna entre Estado de Direito e Democracia. In: A Inclusão do Outro: estudos de teoria política. Tradução de George Sperber e Paulo Astor Soethe. São Paulo: Edições Loyola, 2002, p. 291-292.

${ }^{11}$ Id., Direito e democracia: entre facticidade e validade. Tradução de Flávio Beno Siebeneichler. Rio de Janeiro: Tempo Brasileiro, 1997. v. I, p. 139.

${ }^{12}$ Id., Direito e democracia: entre facticidade e validade. Tradução de Flávio Beno Siebeneichler. Rio de Janeiro: Tempo Brasileiro, 1997. v. II, p. 47.

${ }^{13}$ Id., Sobre a Coesão Interna entre Estado de Direito e Democracia. In: A Inclusão do Outro: estudos de teoria política. Tradução de George Sperber e Paulo Astor Soethe. São Paulo: Edições Loyola, 2002, p. 291 292.

${ }^{14}$ Ibid., p. 294-295.

${ }^{15}$ Ibid., p. 296-297.
} 
pensamento do autor alemão, e o seu olhar acerca do direito é, como não poderia deixar de ser, direcionado por este norte.

Desse modo, Habermas considerar que "o paradigma procedimentalista do direito procura proteger, antes de tudo, as condições do procedimento democrático. Elas adquirem um estatuto que permite analisar, numa outra luz, os diferentes tipos de conflito"16.

O direito positivo, então, pode retirar sua legitimidade de um processo presumidamente racional formativo da vontade e da opinião ${ }^{17}$, da ideia de autodeterminação, pois as pessoas se submetem a um direito que elas mesmas criaram $^{18}$.

Mas há o processo do processo. Ora, o medium linguístico da atividade jurídica é, por sua vez, "a Teoria do Processo [que], ao abrigar uma instituição constitucional, demarca e vincula o próprio discurso jurídico" ${ }^{19}$. Nessa esteira,

A integração social assume forma totalmente reflexiva, pois, na medida em que o direito supre sua cota de legitimação com o auxílio da força produtiva da comunicação, ele utiliza o risco permanente de dissenso, transformando-o num aguilhão capaz de movimentar discursos públicos institucionalizados juridicamente ${ }^{20}$.

É por meio do direito que grandes temas da vida social podem ser deliberados. Esse é o papel do jurídico: ser a regra do jogo democrático, o metro da possibilidade de exercício da vontade do povo. Convém lembrar, destarte, que as pretensões são deduzidas no bojo de um processo, tendo em seus vértices as partes e o juiz. No paradigma jusfilosófico atual, o processo civil recebe os influxos da Constituição e assim se posiciona, inclusive revendo certos $\operatorname{dogmas}^{21}$.

\footnotetext{
${ }^{16}$ HABERMAS, Jünger. Direito e democracia: entre facticidade e validade. Tradução de Flávio Beno Siebeneichler. Rio de Janeiro: Tempo Brasileiro, 1997. v. II, p. 183.

${ }^{17}$ Ibid., p. 319.

${ }^{18}$ Ibid., p. 309.

${ }^{19}$ MADEIRA, Dhenis Cruz. Teoria do processo e discurso normativo: digressões democráticas. In: DIDIER JÚNIOR, Fredie (Org.). Teoria do Processo: Panorama Doutrinário Mundial. Salvador: Editora JusPodivm. 2010, p. 157.

${ }^{20}$ HABERMAS, Jünger. Op. cit., p. 325.

${ }^{21}$ OLIVEIRA, Guilherme Perez de. Elementos para uma leitura do direito processual civil a partir e à luz da constituição - o chamado "modelo constitucional do processo civil" e a garantia de tutela jurisdicional adequada aos direitos alegadamente violado. In: THEODORO JÚNIOR, Humberto; CALMON, Petrônio; NUNES, Dierle (Coord.). Processo e Constituição: os dilemas do processo constitucional e dos princípios processuais constitucionais. Rio de Janeiro: GZ Editora, 2010, p. 173-200.
} 
Ora, para cumprir o mister a que se destina, o direito não pode mais ser visto como um campo de batalha das partes (como no liberalismo) nem um palácio onde reina o juiz com sua palavra final e única dotada de legitimidade. Nesse sentido,

O projeto de realização do direito, que se refere às condições de funcionamento de nossa sociedade, portanto de uma sociedade que surgiu em determinadas circunstâncias históricas, não pode ser meramente formal. Todavia, divergindo do paradigma liberal e do Estado social, este paradigma do direito não antecipa mais um determinado ideal de sociedade, nem uma determinada visão de vida boa ou de uma determinada opção política. Pois ele é formal no sentido de que apenas formula as condições necessárias segundo as quais os sujeitos do direito podem, enquanto cidadãos, entender-se entre si para descobrir os seus problemas e o modo de solucionálos. Evidentemente, o paradigma procedimental do direito nutre a expectativa de poder influenciar, não somente a autocompreensão das elites que operam o direito na qualidade de especialistas, mas também a de todos os atingidos ${ }^{22}$.

Nesse ponto é bem-vinda a contribuição de Häberle, que considera a interpretação um processo aberto, e que a ampliação do número de intérpretes, garante, na verdade, realidade pluralista à interpretação, posto que todo interprete é orientado pela teoria e pela práxis, inclusive os juízes ${ }^{23}$. Portanto, a abertura do processo à interpretação dos vários interessados não conflita com o poder de decisão do magistrado. Ao contrário, dá subsídio para uma decisão que será tanto mais legítima quanto maior for a participação e influência dos destinatários. Significa dizer que

A teoria do discurso explica a legitimidade do direito com o auxílio de processos e pressupostos da comunicação - que são institucionalizados juridicamente - os quais permitem levantar a suposição de que os processos de criação e de aplicação do direito levam a resultados racionais. Do ponto de vista do conteúdo, as normas emitidas pelo legislador político e os direitos reconhecidos pela justiça são racionais pelo fato de os destinatários serem tratados como membros livres e iguais de uma comunidade de sujeitos de direito, ou seja, em síntese: sua racionalidade resulta do tratamento igual das pessoas jurídicas protegidas em sua integridade ${ }^{24}$.

Na modernidade, portanto, a razão é o farol do positivismo, mas a legitimidade é o barco no oceano do pós-positivismo. Desse modo, “as normas do direito só podem obrigar duradouramente enquanto os procedimentos que comandam o seu surgimento forem reconhecidos como legítimos" 25 .

22 HABERMAS, Jünger. Direito e democracia: entre facticidade e validade. Tradução de Flávio Beno Siebeneichler. Rio de Janeiro: Tempo Brasileiro, 1997. v. II, p. 189-190.

23 HÄBELE. Peter. Hermenêutica Constitucional: A sociedade aberta dos intérpretes da constituição: contribuição para a interpretação pluralista e "procedimental" da Constituição. Tradução de Gilmar Ferreira Mendes. Porto Alegre: Sérgio Antônio Fabris Editor, 1997. Reimpressão: 2002, p. 30-31.

${ }^{24}$ HABERMAS, Jünger. Op. cit., p. 153.

${ }^{25}$ HABERMAS, Jünger. Op. cit., p. 105. 
E, a seu turno, a aplicação do direito exige igual gênese na racionalidade e na legitimidade, o que exige que "a teoria da interpretação deve ser garantida sob a influência da teoria da democracia" 26 . O viés procedimentalista do direito só pode ser o viés democrático, e a democracia há de ser encontrada nos trilhos do direito, abrindo-se e fechando-se um círculo virtuoso.

\section{O PROCESSUALISMO CONSTITUCIONAL DEMOCRÁTICO DE DIERLE} NUNES

Uma concepção procedimentalista do direito é deveras animadora porque propõe e permite a construção e o aperfeiçoamento do direito de acordo com o tempo e a cultura, uma vez que a legitimidade desse direito estará exatamente na sua gênese democrática. Ao velar pela proteção das condições necessárias ao procedimento democrático, o procedimentalismo garante a autodeterminação. A teoria de Habermas é, porém, contrafática, normativa. Logo, o direito, e seu principal vetor - o processo -, pode não estar sendo praticado de acordo com os contornos propostos por aquela teoria. Theodoro Júnior et. al. citam como exemplo, do qual pode-se retirada conclusão generalizável, a audiência prevista no art. 342 do CPC de 1973 (art. 376 do Novo (PC), denunciando que a prática forense acabou por não aplicar tal previsão normativa ${ }^{27}$.

Nunes $^{28}$, por exemplo, identifica no Brasil um modelo neoliberal de processo. Não há um agir comunicativo, preocupado com a ética do discurso, nos termos propostos por Habermas, mas um agir orientado para a reaalização de fins, guiado pela razão prática, instrumental. Naquele modelo, portanto, o juiz "passa a atuar de modo estratégico, tentando se

\footnotetext{
${ }^{26}$ HÄBELE. Peter. Hermenêutica Constitucional: A sociedade aberta dos intérpretes da constituição: contribuição para a interpretação pluralista e "procedimental" da Constituição. Tradução de Gilmar Ferreira Mendes. Porto Alegre: Sérgio Antônio Fabris Editor, 1997. Reimpressão: 2002, p. 14.

${ }^{27}$ THEODORO JÚNIOR, Humberto et. al. Novo CPC: fundamentos e sistematização. Rio de Janeiro: Forense, 2015 , p. 81.

${ }^{28}$ NUNES, Dierle José Coelho. Processo Jurisdicional Democrático: Uma Análise Crítica das Reformas Processuais. 1. ed. 3. reimpr. Curitiba: Juruá, 2011, p. 254-255.
} 
livrar do máximo de casos com a maior rapidez procedimental, independente de qualquer concepção social de bem viver" 29 .

Todavia, esse cenário, além de todos os inconvenientes que de regra já possui, ainda torna-se mais tenebroso quando se convida para a cena um processo complexo como uma falência ou uma recuperação judicial. Será muito difícil "eliminar" um processo dessa natureza em curto tempo, e o esforço ensandecido para tanto ainda agrava o risco de decisões e comportamentos judiciais errôneos.

O autor fala na busca da efetivação de um processualismo constitucional democrático ${ }^{30}$, "perspectiva interpretativa que poderá, caso aplicada, garantir que todos os cidadãos possam participar ativamente de todas as esferas jurídicas de que possuam interesse, em um dimensionamento espaço-temporal adequado" 31 . Esse modelo fixa os limites de atuação e constitui condição de possibilidade para que os participantes do processo possam influenciar na tomada da decisão mais adequada ao caso que estiver sendo analisado ${ }^{32}$.

O modelo constitucional de processo é, bem vistas as coisas, o único modelo de processo admissível nos sistemas jurídicos capitaneados por uma constituição que goze de supremacia, como o brasileiro. Por conseguinte, a atuação dos juízes não pode ser tida como a única possível ou adequada, mas uma delas.

Arejado por tais ideias é que Häberle aponta que a interpretação constitucional sempre esteve restrita a uma "sociedade fechada", motivo pelo qual propõe a mudança para uma sociedade aberta dos intérpretes, exatamente por considerar que, ao lado do Poder Judiciário, que tem interpretação definitiva, também participam desse processo de interpretação todas as potências públicas, os cidadãos, grupos ${ }^{33}$.

\footnotetext{
${ }^{29}$ Ibid., p. 254-255.

${ }^{30}$ NUNES, Dierle José Coelho. Processo Jurisdicional Democrático: Uma Análise Crítica das Reformas Processuais. 1. ed. 3. reimpr. Curitiba: Juruá, 2011, p. 260.

${ }^{31}$ Ibid., p. 176.

${ }^{32}$ Idem. Teoria do Processo Contemporâneo: por um procedimento constitucional democrático. Revista da Faculdade de Direito do Sul de Minas, Pouso Alegre, Edição Especial - 2008, p. 13-24, p. 27.

33 HÄBELE. Peter. Hermenêutica Constitucional: A sociedade aberta dos intérpretes da constituição: contribuição para a interpretação pluralista e "procedimental" da Constituição. Tradução de Gilmar Ferreira Mendes. Porto Alegre: Sérgio Antônio Fabris Editor, 1997. Reimpressão: 2002, p. 12-13.
} 
Como visto em Habermas, o destinatário deve ser também o criador da norma, aí residindo a legitimidade da sua submissão a ela. Em linha de consequência, a discussão institucionalizada no processo exige que as partes possam contribuir de modo efetivo para uma decisão racional e legítima.

Daí porque Nunes propõe, para implementação dessa perspectiva democrática, o policentrismo processual, significando a existência não de um único, mas de vários centros e protagonistas com interdependência e co-responsabilidade política e $\operatorname{social}^{34}$, e a comparticipação dos atores processuais - juízes, partes, advogados, membros do Ministério Público e serventuários da Justiça ${ }^{35}$-, cujos argumentos devem ser influir na tomada da decisão, já que vazados no espaço público constituído pelo processo ${ }^{36}$. A proposta de Nunes encontra um lastro - fortuito, diga-se - também em Häberle, uma vez que este chega a apontar um catálogo sistemático dos participantes da interpretação, entre os quais destaca as funções estatais (na decisão vinculante e nos órgãos estatais com poder de decisão vinculante) e os participantes do processo de tomada de decisão (como as partes, inclusive nos procedimentos administrativos; os pareceristas; os peritos; os grupos de pressão organizados; os demais participantes do processo) ${ }^{37}$. Há em Häberle, tanto quanto em Nunes, o interesse em retirar do Estado-juiz o papel de única e/ou última voz capaz de interpretar e aplicar o direito, além de impedir, assim, um comportamento solipsista do julgador. Os interessados na decisão e por ela afetados podem e devem participar da sua construção.

O resgate do papel da participação no espaço público processual de todos os envolvidos (cidadãos ativos), na perspectiva policêntrica e comparticipativa, permitirá o redimensionamento constitucional da atividade processual e do processo, de modo a guindá-lo a seu real papel de garantidor de um debate público e dos direitos fundamentais, de uma estrutura dialógica de formação de provimentos constitucionalmente adequados ${ }^{38}$.

\footnotetext{
${ }^{34}$ NUNES, Dierle José Coelho. Op. cit., p. 198.

35 NUNES, Dierle José Coelho. Processo Jurisdicional Democrático: Uma Análise Crítica das Reformas Processuais. 1. ed. 3. reimpr. Curitiba: Juruá, 2011, p. 258.

${ }^{36}$ Ibid., p. 256.

37 HÄBELE. Peter. Hermenêutica Constitucional: A sociedade aberta dos intérpretes da constituição: contribuição para a interpretação pluralista e "procedimental" da Constituição. Tradução de Gilmar Ferreira Mendes. Porto Alegre: Sérgio Antônio Fabris Editor, 1997. Reimpressão: 2002, p. 20-22.

${ }^{38}$ NUNES, Dierle José Coelho. Op. cit., p. 260.
} 
Cuida-se de um esforço a ser diariamente renovado. É a busca pela concretização de um modelo ideal, aliás, o modelo por excelência. Isso porque o processo jurisdicional não está à disposição de interesses das partes nem da Jurisdição, mas antes é constitutivo do exercício desta, devendo garantir direitos de participação, que é o que confere legitimidade ao provimento jurisdicional $^{39}$.

Em outras palavras, o "Direito deve fundar-se tão somente no princípio democrático", compreendido como "institucionalização de processos estruturados por normas que garantam a possibilidade de participação discursiva dos cidadãos no processo de tomada de decisões" 40 . O medium do direito, que é o processo, deve, pois, igualmente fundar-se em bases democráticas, o que exige a garantia de participação equânime de todos os envolvidos. Tanto é que se considera que nem a bandeira de garantia da autoridade e unidade da lei federal pode justificar uma supremacia do interesse público sobre o interesse das partes, reconhecendo que ambos devem se relacionar de modo co-produtivo ${ }^{41}$.

É o que se pretende quando se diz "a inserção do contraditório no rol das garantias constitucionais decorre da exigência lógica e democrática da co-participação paritária das partes, no procedimento formativo da decisão jurisdicional que postulam no processo" 42 . O agente do processo - todos e cada um - tem garantia de poder participar e influir na decisão.

Em síntese: "Pensar um novo modelo de jurisdição e de processo, abertos à cooperação e ao diálogo, exige espíritos livres que estejam preparados para as eventuais derivas que venham a seguir" ${ }^{\prime 3}$. Nessa esteira, o novo Código de Processo Civil, no plano normativo, criou

\footnotetext{
${ }^{39}$ OLIVEIRA, Marcelo Andrade Cattoni de. Contribuições para uma Teoria Discursiva da Constituição do Processo Constitucional a Partir do Caso Brasileiro. In: THEODORO JÚNIOR, Humberto; CALMON, Petrônio; NUNES, Dierle (Coord.). Processo e Constituição: os dilemas do processo constitucional e dos princípios processuais constitucionais. Rio de Janeiro: GZ Editora, 2010, p. 95-130.

${ }^{40}$ OLIVEIRA, Marcelo Andrade Cattoni de. Direito, política e filosofia. Rio de Janeiro: Lumen Juris, 2007, p. 142.

${ }^{41}$ BAHIA, Alexandre Gustavo Melo Franco. Os Recursos Extraordinários e a Co-originalidade dos Interesses Público e Privado no Interior do Processo: reformas, crises e desafios à jurisdição desde uma compreensão procedimental do Estado Democrático de Direito. In: MACHADO, Felipe Daniel Amorim; OLIVEIRA, Marcelo Andrade Cattoni. Constituição e Processo: a contribuição do processo ao constitucionalismo democrático brasileiro. Belo Horizonte: Del Rey, 2009, p. 371.

${ }^{42}$ BRÊTAS, Ronaldo de Carvalho Dias. Processo Constitucional e Estado Democrático de Direito. Belo Horizonte: Del Rey, 2010. p. 91.

${ }^{43}$ MORAIS, José Luis Bolzan de; SALDANHA, Jânia Maria Lopes; ESPINDOLA, Ângela Araújo da Silveira. Jurisdição Constitucional e Participação Cidadã: por um processo formal e substancialmente vinculado aos princípios político-constitucionais! In: MACHADO, Felipe Daniel Amorim; OLIVEIRA, Marcelo Andrade Cattoni. Constituição e Processo: a contribuição do processo ao constitucionalismo democrático brasileiro. Belo Horizonte: Del Rey, 2009, p. 115.
} 
instrumentos capazes de permitir a comparticipação e o policentrismo, já que se trata de "um código de todos os sujeitos processuais" ${ }^{44}$. Destrate,

Para que o processo de fato mereça o qualitativo de democrático/justo, e se torne real o clima de colaboração entre o juiz e as partes, a nova lei impõe uma conduta leal e de boa-fé, não só dos litigantes, mas também do magistrado, a quem se atribuíram os deveres de esclarecimento, de diálogo, de prevenção e de auxílio [...], criando-se um novo ambiente normativo contrafático de indução à comparticipação (em decorrência dos comportamentos não cooperativos).

A concepção procedimentalista do direito, sendo contrafática, coaduna com o próprio direito. O direito em si não é, não está no mundo do ser, mas do dever ser. Daí, o desafio hodierno é dar efetividade ao quanto previsto no Novo CPC, evitando-se ocorrências como a citada no primeiro parágrafo desta seção. Aliás,

devemos afastar aqueles argumentos recorrentes "de que isto não funcionará porque sempre foi diferente", uma vez que negam exatamente o papel corretivo e a função contrafática do Direito, que se presta a fiscalizar e a implementar balizas normativas (correção normativa) a que os direitos, especialmente fundamentais, se prestam ${ }^{45}$.

O porvir, o auspicioso, a utopia, a esperança podem parecer de início meros devaneios inconcretizáveis. Mas é por meio desse movimento de esforço que o homem tem rompido as barreiras e superados os limites seus e do ambiente onde inserido, desde as cavernas até as presentes sociedades complexas. O hoje, certo e determinado, um dia foi o futuro extravagante e fantasioso.

\section{AUDIÊNCIA DE GESTÃO DEMOCRÁTICA}

A recuperação judicial é um instituto que visa "a superação da situação de crise econômico-financeira do devedor, a fim de permitir a manutenção da fonte produtora, do emprego dos trabalhadores e dos interesses dos credores", conforme estatui o art. 47 da Lei ${ }^{\circ}$ $11.101 / 2005$.

\footnotetext{
44 THEODORO JÚNIOR, Humberto et. al. Novo CPC: fundamentos e sistematização. Rio de Janeiro: Forense, 2015, p. 78 .

${ }^{45}$ NUNES, Dierle José Coelho. A função contrafática do Direito e o Novo CPC. Revista do Advogado, São Paulo, n. 126 , p. $51-55$, mai. 2015 , p. 54.
} 
Como se constata pelo próprio nome, a recuperação judicial se dá no bojo de um processo judicial. Todavia, ao contrário do modelo clássico de demanda, angularizado por autor, réu e juiz, "o direito falimentar brasileiro adotou a natureza jurídica processual da recuperação de empresas" ${ }^{\sharp 6}$, com nítida característica contratual.

Tem-se, portanto, que não obstante o pedido de recuperação judicial estar sujeito à direção e homologação da autoridade judiciária competente, a fundamental representatividade e participação dos credores na decisão de aprovação do plano de recuperação da empresa imprime-lhe uma natureza contratual ${ }^{47}$.

Significa dizer que na recuperação judicial o papel do juiz é bastante limitado, uma vez que a decisão de aprovar ou não o plano que dispõe sobre a recuperação da empresa compete exclusivamente aos credores. Assim,

O Estado-Juiz vai atuar para criar o ambiente adequado para que a empresa viável consiga superar a situação de crise.

[...]

Importante notar que o Estado não deve substituir a iniciativa privada nessa função de encontrar solução para a crise da empresa, mas apenas deve atuar para corrigir as distorções do sistema econômico. A recuperação judicial só tem lugar quando as estruturas do livre mercado falharam ${ }^{48}$.

Desse modo, os credores compõem uma verdadeira sociedade de interessados que discutirão entre si e com a devedora sobre o futuro desta. $O$ juiz não tem, portanto, uma função proeminente, o que atrai, inclusive, a proposição de Häberle, para quem “o juiz constitucional já não interpreta, no processo constitucional, de forma isolada: muitos são os participantes do processo; as formas de participação ampliam-se acentuadamente" 49 . Essa conclusão coaduna com a proposição deste artigo: a audiência de gestão democrática.

Trata-se de metodologia destinada a questões mais complexas do processo de recuperação judicial ou falência. Nesses processos, a audiência de gestão democrática tem lugar sempre que o juiz identificar a necessidade de decidir temas relevantes para imprimir andamento ao feito com eficiência, tais como arrecadação, avaliação e alienação de ativos, o

\footnotetext{
${ }^{46}$ RESTIFFE, Paulo Sérgio. Recuperação de Empresas: De Acordo com a Lei n. 11.101, de 09.02.2005. Barueri: Manole, 2008, p. 404.

47 MARZAGÃO, Lídia Valério. A recuperação judicial. In: MACHADO, Rubens Approbato (Coord.). Comentários à Nova Lei de Falências e Recuperação de Empresas: Doutrina e Prática. São Paulo: Quartier Latin, 2005, p. 93-94.

${ }^{48}$ COSTA, Daniel Carnio (Coord.). Comentários Completos à Lei de Recuperação de Empresas e Falências. Curitiba: Juruá, 2015, v. 1, p. 22.

49 HÄBELE. Peter. Hermenêutica Constitucional: A sociedade aberta dos intérpretes da constituição: contribuição para a interpretação pluralista e "procedimental" da Constituição. Tradução de Gilmar Ferreira Mendes. Porto Alegre: Sérgio Antônio Fabris Editor, 1997. Reimpressão: 2002, p. 41.
} 
modo de proceder às vendas e a utilização de recursos e bens, por exemplo. Temas menos complexos devem ser decididos pelo juiz em decisões segundo o modelo tradicional, até para preservar o êxito da audiência. Em seguida deverá ser publicada a pauta, de modo que todos os interessados tenham conhecimento prévio dos temas que serão discutidos e objeto de decisão.

$\mathrm{Na}$ audiência o magistrado seguirá a ordem da pauta, oportunizando aos interessados a oferta de suas manifestações - escritas ou orais -, que serão analisadas pelo magistrado na própria audiência. O juiz, assim, decidirá as questões, uma a uma, podendo determinar tarefas a serem cumpridas pelos atores do processo. As decisões que contarem com a concordância de todos serão assim registradas na ata da audiência, evitando-se recursos protelatórios. Ao final, o magistrado já designará nova audiência de gestão democrática, cuja finalidade será acompanhar o cumprimento das atribuições que tiverem sido dadas aos agentes do processo, além da apreciação, debate e decisão de novos temas. Portanto, cada audiência é una, mas nada impede a designação de novas assentadas ${ }^{50}$.

Pela gestão democrática do processo, o juiz não decide sozinho uma questão complexa; ao contrário, é aplicada uma metodologia para que todos os envolvidos e interessados (Ministério Público, Comitê de Credores, administrador judicial, devedora, credores e outros interessados que houver) participem de audiências públicas, contribuindo e influenciando na formação das decisões a serem tomadas ${ }^{51}$. O modelo de gestão processual ora analisado tem, é verdade, caráter democrático, porque "todos podem participar da condução do processo, o que aproxima a população do Poder Judiciário. Todos os interessados sentem-se importantes para a condução do feito e próximos ao juízo, o que os torna menos resistentes e mais colaborativos"52, além de que o juiz também atua como mediador ${ }^{53}$.

Talvez esse viés democrático e a possibilidade de instrumentalizar, de fato, no processo judicial, as ideias de comparticipação e policentrismo, sejam as maiores contribuições desse

\footnotetext{
${ }^{50}$ Disponível em: <http://www.premioinnovare.com.br/proposta/audiencias-de-gestao-democratica-de-processosde-insolvencia-falencias-e-recuperacoes-judiciais-de-empresas-20150316113436349169/print>. Acesso em 20 mai. 2018.

${ }^{51}$ COSTA, Daniel Carnio. Reflexões sobre processos de insolvência: divisão equilibrada de ônus, superação do dualismo pendular e gestão democrática de processos. Cadernos Jurídicos da Escola Paulista de Magistratura, São Paulo, ano 16, nº 39, p. 59-77, Janeiro-Março/2015, p. 76.

${ }^{52}$ Disponível em: <http://www.premioinnovare.com.br/proposta/audiencias-de-gestao-democratica-de-processosde-insolvencia-falencias-e-recuperacoes-judiciais-de-empresas-20150316113436349169/print>. Acesso em 20 mai. 2018

${ }^{53}$ Ibid.
} 
modelo de audiências e aí está sua singularidade em relação às demais audiências tradicionalmente realidades. Nestas, como visto alhures, observa-se, no mais das vezes, parca influência das partes e de seus advogados na tomada de decisões, pouco espaço para a discussão aprofundada dos temas e o magistrado mais preocupado em ser célere para realizar um grande número de audiências, tudo decorrência do neoliberalismo processual.

Por outro lado, a preocupação que se levanta é se a audiência de gestão democrática, ao contrário do que é sua proposta, não poderia acabar por atrasar a finalização dos processos, até mesmo pela introdução de mais audiências em um Judiciário já afligido. A questão não é simples, de fato, mas não pode prevalecer. Isso porque já por mandamento constitucional o processo deve ter tramitação célere, mas sem descurar da garantia aos meios para sua razoável duração, do devido processo legal e da fundamentação das decisões $\left(\mathrm{CF}\right.$, art. $5^{\circ}$, incisos LXXVIII e LIV e art. 93, inciso IX). Contudo, a contribuição da audiência de gestão democrática também não deve ser banalizada e aplicada sem critérios. Sua recomendação se dá para processos mais complexos, que envolvam maior número de interessados e questões jurídicas e fáticas complexas.

É preciso que haja, na data da audiência, todo o suporte de fatos e provas (como laudos periciais, por exemplo) nos autos para que as partes e o magistrado possam analisar, debater e decidir, de modo que a audiência só deve ser designada nesses momentos oportunos. O magistrado também deve estar auxiliado na audiência e designar tarefas para serventuários, partes e auxiliares da justiça. A funcionalidade da audiência se dá muito por conta da pauta, de modo que há uma sequência de temas a serem enfrentados e decididos. Essa influência das partes na decisão, além de garantir sua legitimidade, contribui sobremaneira para a celeridade, uma vez que afasta vários recursos com o fato de constar em ata a renúncia ao interesse em recorrer.

Por esses motivos é que a audiência de gestão democrática é importante ferramenta à disposição do juiz, também podendo ser requerida por qualquer interessado, e isso sempre que houver questões complexas que recomendem discussão pelos atores processuais e que possam ser objeto de subsequente decisão na própria assentada. A adoção dessa metodologia traz, portanto, diversos resultados positivos na condução do processo, o que viabiliza a salvaguarda dos direitos nele versados. O grande número de envolvidos; o volume de informações, argumentos, fatos e provas; a complexidade, enfim, dos processos de recuperação judicial e de 
falência, cria o ambiente em que essa audiência se apresenta como eficiente método. Aliás, pelas mesmas razões, a audiência de gestão democrática pode ser utilizada em outras espécies de demandas como, por exemplo, as ações coletivas e outros processos mais complexos, como os que envolvam vários interessados ou que exijam a contribuição de especialistas. "E o melhor: a aplicação do modelo de gestão democrática de processos é imediata e independe de alteração legislativa" ${ }^{4}$. Ora,

\begin{abstract}
Além de imprimir maior celeridade ao processo decisório, a Gestão Democrática de Processos apresenta ainda outras vantagens: garante a participação das partes e interessados no processo decisório, induz maior comprometimento de todos aqueles que atuam no processo, assegura maior transparência ao processo, propicia maior fiscalização sobre o andamento processual e, ainda, franqueia aos interessados o fornecimento ao juízo de informações relevantes e úteis sobre aspectos diversos do processo [...], colaborando para a maior qualidade da decisão judicial ${ }^{55}$.
\end{abstract}

As partes do processo não mais se consideram apenas envolvidas no problema, mas se reconhecem como autores das soluções buscadas ${ }^{56}$. A audiência de gestão democrática do processo, ao permitir a efetiva e direta participação dos interessados na tomada de decisões, no espaço do processo judicial, é um expediente democrático válido e muito apropriado ao momento hodierno, concretizando o modelo do processualismo constitucional democrático ${ }^{57}$. "O processo passa a ser um instrumento ético de realização de direitos" 58 .

Tem-se que a oralidade pode garantir maior eficiência nos debates e na tomada da decisão judicial. Nunes e Bahia $^{59}$ propõem, inclusive, a retomada da discussão sobre a oralidade, apontanda como debates orais presenciais permitem esclarecimentos acerca das questões controvertidas, estimulando acordos e evitado decisões surpresa.

\footnotetext{
${ }^{54}$ Ibid., p. 76.

${ }^{55}$ COSTA, Daniel Carnio. Op. cit., p. 76.

${ }^{56}$ Id., Comentários Completos à Lei de Recuperação de Empresas e Falências. Curitiba: Juruá, 2015, v. 1, p. 55 .

57 THEODORO JÚNIOR, Humberto et. al. Novo CPC: fundamentos e sistematização. Rio de Janeiro: Forense, 2015 , p. 80.

${ }^{58}$ Disponível em: <http://www.premioinnovare.com.br/proposta/audiencias-de-gestao-democratica-de-processosde-insolvencia-falencias-e-recuperacoes-judiciais-de-empresas-20150316113436349169/print>. Acesso em 20 mai. 2018.

${ }^{59}$ NUNES, Dierle José Coelho; BAHIA, Alexandre Gustavo Melo Franco. Por um paradigma prático de processo. In: DIDIER JÚNIOR, Fredie (Org.). Teoria do Processo: Panorama Doutrinário Mundial. Salvador: Editora JusPodivm. 2010, p. 159-180.
} 
A litigância de má-fé tende a diminuir significativamente, posto que comportamentos processuais indevidos podem ser mais facilmente escondidos atrás de petições escritas, mas não resistem ao desvelamento permitido pela confrontação oral.

Alterar a verdade dos fatos, litigar contra texto expresso de lei ou contra fato incontroverso, induzir a erro o magistrado, proceder de modo temerário são condutas que têm muito menos chances de durar no tempo processual e, ainda menos, de obterem êxito praticadas em um ambiente marcado pela oralidade. $\mathrm{O}$ argumento contrário, a prova em sentido oposto, a denúncia da atuação inescrupulosa seria imediatamente apresentada, minando o arsenal daquele que quer usar do processo para atrasar a solução da causa ou para impedir a implementação dos direitos de quem os tem. É bem de ver:

em um tempo em que se pretende seja o processo rápido, informal e simples, aumentar o número de sujeitos que dele participam imprime um movimento contrário às aspirações contemporâneas de Justiça célere, porque agrega maior complexidade ao ato de julgar.

Mas talvez seja preciso reconhecer que a cultura da urgência e da virtualização substituída pelo inusitado do encontro e da oralidade, permite que seja prestada uma Justiça com mais qualidade e maior comprometimento social ${ }^{60}$.

A oralidade trata-se - é o que se pensa - de mecanismo apto a concretizar a comparticipação e o policentrismo ao trazer para o espaço público processual da audiência o plexo de argumentos e provas dos agentes do processo, o debate entre todos eles (e não apenas entre as partes, como no liberalismo, nem só o monólogo do magistrado, como no socialismo) e a chegada à decisão de modo mais transparente e responsável: uma decisão construída pelos partícipes, por todos eles.

As audiências de gestão democrática do processo se inserem no paradigma da concepção jurídica procedimentalista.

\footnotetext{
${ }^{60}$ MORAIS, José Luis Bolzan de; SALDANHA, Jânia Maria Lopes; ESPINDOLA, Ângela Araújo da Silveira. Jurisdição Constitucional e Participação Cidadã: por um processo formal e substancialmente vinculado aos princípios político-constitucionais! In: MACHADO, Felipe Daniel Amorim; OLIVEIRA, Marcelo Andrade Cattoni. Constituição e Processo: a contribuição do processo ao constitucionalismo democrático brasileiro. Belo Horizonte: Del Rey, 2009, p. 134-135.
} 


\section{CONCLUSÃO}

A concepção jurídica procedimentalista de Habermas fornece subsídios fundamentais para a compreensão do direito como medium da passagem das sociedades simples para as complexas, com diferenciação social. Na modernidade, não há mais uma única visão correta de mundo, uma única resposta pré-concebida e meramente aplicável a cada caso concreto. Daí o paradigma procedimentalista do direito, que se apresenta como superação dos paradigmas liberal e republicano.

O direito é criado pelo processo democrático em bases racionais, sendo o modo institucionalizado de debates públicos. Por sua vez, o processo é o medium da atividade jurídica, é o ambiente que viabiliza a comunicação dos agentes, é o espaço público que instrumentaliza aquelas discussões, supondo a chegada a resultados racionais.

É por isso que se deve pensar em um processualismo constitucional democrático, com Nunes, o qual parte da premissa de que todos os agentes processuais, que se submeterão à decisão, devem poder participar da sua formação, influenciando-a. É o fato de os destinatários da norma participarem da sua criação e da sua interpretação e aplicação na qualidade de sujeitos livres e iguais que faz com que as decisões sejam ditas como racionais.

O policentrismo processual, a comparticipação, a co-responsabilidade e o contraditório são imprescindíveis para a concretização do modelo constitucional de processo. É a ideia de uma sociedade aberta de intérpretes, de Häberle, com os contornos do espaço processual. E isso, ao contrário do que possa parecer, não afeta o papel contramajoritário a ser exercido pelo Poder Judiciário, justamente porque a participação e a influência das partes no processo não retiram do órgão julgador a competência para a decisão. Participar e influir garante legitimidade da decisão, mesmo que esta não seja a mais desejada por uma ou outra parte.

Nessa perspectiva se inserem as audiências de gestão democrática do processo, que são indicadas aos processos de recuperação judicial e falência. Todavia, também se pode utilizar tal modelo em outros processos complexos, como a ação direta de inconstitucionalidade e a ação declaratória de constitucionalidade, dado o amplo rol de legitimados ativos (CF, art. 103); a ação civil pública (Lei n 7.347/1985); e até mesmo as ações coletivas propostas por associações 
(CF, art. $\left.5^{\circ}, \mathrm{XXI}\right)$ e por sindicatos (CF, art. $8^{\circ}$, III) e dos índios, suas comunidades e organizações (CF, art. 232), além do mandado de segurança coletivo (CF, art. 5º LXX).

Na verdade, sempre que houver questões complexas a serem decididas, ou urgência da decisão, ou grande número de interessados, referida audiência pode se fazer recomendada, sendo aplicável a todos os processos judiciais, restando, pois, confirmadas as hipóteses.

A concepção contrafática do direito e do seu paradigma procedimental merecem compreensão não como uma irrealidade, mas como um dever ser, um valor ético a ser alcançado. $\mathrm{O}$ arquétipo da audiência de gestão democrática, destarte, se insere na perspectiva procedimentalista, nesse âmbito de busca por uma prática processual adequada ao modelo constitucional de processo e apresenta-se como condição de possibilidade de os agentes processuais participarem de modo ativo e paritário e influenciarem a formação da decisão.

\section{REFERÊNCIAS}

BAHIA, Alexandre Gustavo Melo Franco. Os Recursos Extraordinários e a Co-originalidade dos Interesses Público e Privado no Interior do Processo: reformas, crises e desafios à jurisdição desde uma compreensão procedimental do Estado Democrático de Direito. In: MACHADO, Felipe Daniel Amorim; OLIVEIRA, Marcelo Andrade Cattoni. Constituição e Processo: a contribuição do processo ao constitucionalismo democrático brasileiro. Belo Horizonte: Del Rey, 2009.

BRASIL. Constituição Federal, de 05 de outubro de 1988. Disponível em: <http://www.planalto.gov.br/ccivil_03/constituicao/constituicaocompilado.htm>. Acesso em 03 jun. 2018.

BRASIL. Lei $\mathrm{n}^{\mathrm{o}} 7.347$, de 24 de julho de 1985 . Disponível em: <http://www.planalto.gov.br/ccivil_03/LEIS/L7347orig.htm>. Acesso em 03 jul. 2018.

BRASIL. Lei $\mathrm{n}^{\mathrm{o}}$ 8.078, de 11 de setembro de 1990. Disponível em: <http://www.planalto.gov.br/ccivil_03/Leis/L8078compilado.htm>. Acesso em 03 ago. 2018.

BRASIL. Lei $\mathrm{n}^{\circ}$ 11.101, de 09 de fevereiro de 2005. Disponível em: <http://www.planalto.gov.br/ccivil_03/_ato2004-2006/2005/lei/111101.htm>. Acesso em 03 jun. 2018.

BRASIL. Lei $\mathrm{n}^{\mathrm{o}}$ 13.105, de 16 de março de 2015. Disponível em: <http://www.planalto.gov.br/ccivil_03/_ato2015-2018/2015/lei/113105.htm>. Acesso em 03 jun. 2018. 
BRÊTAS, Ronaldo de Carvalho Dias. Processo Constitucional e Estado Democrático de Direito. Belo Horizonte: Del Rey, 2010.

COSTA, Daniel Carnio (Coord.). Comentários Completos à Lei de Recuperação de Empresas e Falências. Curitiba: Juruá, 2015, v. 1.

COSTA, Daniel Carnio. Reflexões sobre processos de insolvência: divisão equilibrada de ônus, superação do dualismo pendular e gestão democrática de processos. Cadernos Jurídicos da Escola Paulista de Magistratura, São Paulo, ano 16, nº 39, p. 59-77, Janeiro-Março/2015.

HÄBERLE. Peter. Hermenêutica Constitucional: A sociedade aberta dos intérpretes da constituição: contribuição para a interpretação pluralista e "procedimental" da Constituição. Tradução de Gilmar Ferreira Mendes. Sérgio Antônio Fabris Editor: Porto Alegre, 1997. Reimpressão: 2002.

HABERMAS. Direito e democracia: entre facticidade e validade. 2 ed. Tradução de Flávio Beno Siebeneichler. Rio de Janeiro: Tempo Brasileiro, 1997. v. I.

HABERMAS, Jünger. Direito e democracia: entre facticidade e validade. Tradução de Flávio Beno Siebeneichler. Rio de Janeiro: Tempo Brasileiro, 1997. v. II.

HABERMAS, Jünger. Entre naturalismo e religião: estudos filosóficos. Tradução de Flávio Beno Siebeneichler. Rio de Janeiro: Tempo Brasileiro, 2007.

HABERMAS, Jünger. Sobre a Coesão Interna entre Estado de Direito e Democracia. In: . A Inclusão do Outro: estudos de teoria política. Tradução de George Sperber e Paulo Astor Soethe. São Paulo: Edições Loyola, 2002, p. 284-297.

HABERMAS, Jünger. Sobre o alcance e as limitações das teorias. In: Passado como futuro. Tradução de Flávio Beno Siebeneichler. Rio de Janeiro: Tempo Brasileiro, 1993.

MADEIRA, Dhenis Cruz. Teoria do processo e discurso normativo: digressões democráticas. In: DIDIER JÚNIOR, Fredie (Org.). Teoria do Processo: Panorama Doutrinário Mundial. Salvador: Editora JusPodivm. 2010, p. 135-158.

MARZAGÃO, Lídia Valério. A recuperação judicial. In: MACHADO, Rubens Approbato (Coord.). Comentários à Nova Lei de Falências e Recuperação de Empresas: Doutrina e Prática. São Paulo: Quartier Latin, 2005.

MORAIS, José Luis Bolzan de; SALDANHA, Jânia Maria Lopes; ESPINDOLA, Ângela Araújo da Silveira. Jurisdição Constitucional e Participação Cidadã: por um processo formal e substancialmente vinculado aos princípios político-constitucionais! In: MACHADO, Felipe Daniel Amorim; OLIVEIRA, Marcelo Andrade Cattoni. Constituição e Processo: a contribuição do processo ao constitucionalismo democrático brasileiro. Belo Horizonte: Del Rey, 2009.

NUNES, Dierle José Coelho; BAHIA, Alexandre Gustavo Melo Franco. Por um paradigma prático de processo. In: DIDIER JÚNIOR, Fredie (Org.). Teoria do Processo: Panorama Doutrinário Mundial. Salvador: Editora JusPodivm. 2010, p. 159-180. 
NUNES, Dierle José Coelho. A função contrafática do Direito e o Novo CPC. Revista do Advogado, São Paulo, n. 126, p. 51-55, mai. 2015.

NUNES, Dierle José Coelho. Da Teoria Fazzalariana de Processo - O Processo como Espécie de Procedimento Realizado em Contraditório e a Difusão dos Módulos Processuais como Mecanismo de Controle da Função Estatal. Revista IOB Direito Civil e Processual Civil, São Paulo, ano VIII, n. 43, p. 212-215, set./out. 2006.

NUNES, Dierle José Coelho. Processo Jurisdicional Democrático: Uma Análise Crítica das Reformas Processuais. 1. ed. 3. reimpr. Curitiba: Juruá, 2011.

NUNES, Dierle José Coelho. Teoria do Processo Contemporâneo: por um procedimento constitucional democrático. Revista da Faculdade de Direito do Sul de Minas, Pouso Alegre, Edição Especial - 2008, p. 13-24.

OLIVEIRA, Guilherme Perez de. Elementos para uma leitura do direito processual civil a partir e à luz da constituição - o chamado "modelo constitucional do processo civil" e a garantia de tutela jurisdicional adequada aos direitos alegadamente violado. In: THEODORO JÚNIOR, Humberto; CALMON, Petrônio; NUNES, Dierle (Coord.). Processo e Constituição: os dilemas do processo constitucional e dos princípios processuais constitucionais. Rio de Janeiro: GZ Editora, 2010, p. 173-200.

OLIVEIRA, Marcelo Andrade Cattoni de. Contribuições para uma Teoria Discursiva da Constituição do Processo Constitucional a Partir do Caso Brasileiro. In: THEODORO JÚNIOR, Humberto; CALMON, Petrônio; NUNES, Dierle (Coord.). Processo e Constituição: os dilemas do processo constitucional e dos princípios processuais constitucionais. Rio de Janeiro: GZ Editora, 2010, p. 95-130.

OLIVEIRA, Marcelo Andrade Cattoni de. Direito, política e filosofia. Rio de Janeiro: Lumen Juris, 2007.

RESTIFFE, Paulo Sérgio. Recuperação de Empresas: De Acordo com a Lei n. 11.101, de 09.02.2005. Barueri: Manole, 2008.

SIMIONI, Rafael Lazzarotto. Direito e Racionalidade Comunicativa. A Teoria discursiva do direito no pensamento de Jurgen Habermas. Curitiba: Juruá, 2007.

THEODORO JÚNIOR, Humberto et. al. Novo CPC: fundamentos e sistematização. Rio de Janeiro: Forense, 2015, p. 81.

Data de Submissão: 07/01/2020

Data de Aceite: 02/03/2020 